\title{
Hygiene at work: An engineering perspective on the development of hygiene science
}

\author{
Presented by Peter J Pityn PhD MEng
}

PJ Pityn. Hygiene at work: An engineering perspective on the development of hygiene science. Can J Infect Dis Med Microbiol 2008;19(2):165-168.

The present article examines the work of contemporary hygiene practitioners. Discussion converges from a broad examination of hygiene at work in our society serving the common good to occupational hygiene in the workplace. The article considers the expanding role of hygiene today, juxtaposed against the lack of awareness and perceptions of hygiene. It considers some of the current social challenges facing hygiene, perceptions of risk and problems specifically encountered by occupational hygienists.

Key Words: Bioterrorism; Chemical hazards; Dose, Environmental health; Hygiene; Indoor air quality; Microbiological hazards; Mold exposures; Occupational carcinogens; Pandemics; Risks; Safe limit; Stanier Institute

\section{Hygiène au travail : Point de vue de l'ingénierie sur la création d'une science de l'hygiène industrielle}

Le présent article se penche sur le travail des spécialistes en hygiène du travail. Cette analyse procède d'un vaste examen des pratiques en matière d'hygiène industrielle dans notre société pour le bien commun et étudie son application dans les lieux de travail. L'article se penche sur le rôle croissant de l'hygiène de nos jours, sur fond de perceptions erronées et de connaissances généralement insuffisantes dans le domaine. On y aborde en outre certains des défis sociétaux actuels relativement à l'hygiène, notamment la perception des risques et les problèmes auxquels sont particulièrement confrontés les hygiénistes en milieu de travail.
$\mathrm{H}$ ygiene as scientific activity fulfills a vital role in most societies! Strange then, that so few people are aware of hygiene per se or can articulate what this entails. This limited appreciation of hygiene is perhaps the greatest challenge facing further development of hygiene science. There are, in fact, many everyday practitioners of hygiene, most of whom would not describe themselves as hygienists or necessarily state hygiene as the raison d'être for their activities.

Valerie Curtis (1), in a previous Stanier public lecture exploring the natural history of hygiene, asked, 'what is hygiene?' She positions hygiene as somewhere between filth and cleanliness, between private and public, between science and morality. As if this is not enough ambivalence, ask a microbiologist, a historian or an anthropologist, and you will get further different answers. Hygienists struggle to explain themselves, as if there is a need to legitimize their role. This ambiguity limits an appreciation of hygiene and, therefore, a clearer statement about the definition of hygiene is needed.

The present article examines the work of contemporary hygiene practitioners. In this context, the title plays on the words 'hygiene at work', with a twofold meaning. One side examines where hygiene is at work in our society, serving the common good. From this general starting point, the discussion narrows to address the specific subject of hygiene at work in the workplace - the domain of 'occupational hygiene'.

\section{HYGIENE IS DEFINED BY PURPOSE}

'What is hygiene?' Simply put, hygiene is not a single scientific entity, but the collaboration of many human sciences, disciplines, professions and technologies, with the common purpose of protecting individuals and communities from harmful exposures. Morris Goldner (2), President of the Stanier Institute (Ottawa, Ontario), defines hygiene science as "a wide involvement of disciplines such as physiology, nutrition, immunology, microbiology, parasitology, toxicology, etc... with a common aim to produce a healthy and safe environment for the sake of protecting and preventing individuals and populations from harm and disease".

Dr Goldner's statement reflects the traditional roots of hygiene in the health sciences. Nevertheless, he acknowledges that hygiene encompasses all scientific efforts that serve to protect us and prevent harm. Hygiene has evolved beyond the traditional boundaries of infection control and elimination of toxin exposures. There is a need to reconsider the modern hygiene practitioner's role. In some cases, this has expanded considerably beyond prevention and protection. The hygiene practitioner of today applies these skills and knowledge to fulfill the broader objective of ensuring well-being and enhanced living conditions.

\section{DEVELOPMENT OF HYGIENE}

Many landmark accomplishments in the early development of hygiene were founded in parallel with broader developments in science (3). The evolution in the diversity and type of tools provided by the expanding universe of science allowed hygiene to advance and specialize. As other sciences evolved, hygienists were provided with new tools to recognize and deal with increasingly complex issues. 
At each 'age' in history, hygienists faced new challenges in efforts to protect people, and over time they were increasingly better equipped. The early challenges were physical harm and safety risks to well-being. Then came recognition of the role of infectious and toxic substances. Today, the full extent of hygiene goes well beyond these frontiers of 'hygiene' to face risks associated with new technologies (noise, electromagnetic radiation, reduced physical demands of work and impact on fitness, and modified foods), new materials (synthetic, nonbiodegradable and unknown carcinogenicity), new organisms (evolved resistance, transplanted geographically and genetically engineered) and new activities (the changing nature of work, unsustainable development and globalization).

\section{HYGIENE TODAY}

With the current level of specialization, hygiene incorporates individual disciplines distinguishable as themes within toxicology, environmental health, environmental microbiology, health science, civil engineering and pollution chemistry. Those who consider themselves as 'hygienists' are few compared with those who perform hygiene work on a day-to-day basis. For example, one of the largest impacts in this area is from engineers. In regard to water treatments, sanitation and providing safe drinking water, they do as much, if not more, than other groups to protect the health and welfare of the public. Thus, hygienists have diffused professionally into various other disciplines.

Within the umbrella of occupational health disciplines, one group has members professionally designated as hygienists. 'Occupational hygienists' may be the only group to identify themselves in this manner. Occupational hygiene deals with hygiene issues in the work environment. The objective of occupational hygiene has traditionally been to protect workers from hazards which arise during or as a result of employment (4).

Occupational hygiene overlaps with public health on many issues (ie, exposure to a toxic contaminant such as asbestos or a microbiological agent such as Legionella), but the recipient of benefit differs. One serves to protect the public, while the other protects the worker. There are many instances in which the public interest and the workplace are one and the same, thus, distinctions are arbitrary and more jurisdictional than professional. With the changing nature of work and the increase in the number of home-based businesses, distinctions between home and work environments disappear. In the industrialized world, this seems to be a reflection of the new technological era, but in many developing countries this is reality, simply the way that families, communities and societies exit.

\section{THE OCCUPATIONAL HYGIENE MISSION}

Protecting workers against disease, ill-health or impairment due to chemical, microbiological and physical health hazards, not only during, but after work, has been the traditional goal of occupational hygiene. Prevention of occupational diseases emanating from the workplace due to toxic exposures has been one of the primary roles. Determining when to act and what to respond to is not always obvious. For short-acting agents, the health effects on individuals manifest at work, but for others, the delay of onset or progression of disease 'after work' may develop over hours, months or many years.

The cause and effect connections to work are not always easy to demonstrate, even when they occur contemporaneously in the workplace. The situation is more difficult to sort out if ill effects occur at work, but are not related to exposures at work, or are not induced by work activities. The confounding effects of home life, leisure activities, smoking, consumption of prescription and over-the-counter drugs, individual stress coping mechanisms and personal motivations can all have a bearing $(5,6)$.

Identifying the factor or combination of exposures that are a risk to the worker requires the occupational hygienist to know and anticipate potential hazards. This may come from a diagnosis of the work environment to identify contaminant sources; from a determination of human interactions with tools and equipment; or from the signs, symptoms, concerns or experience of the worker that provides clues to the cause. Examination of the industrial processes and modern facilities which fabricate, manufacture and blend, converting raw materials into final products for consumers or into intermediate products feeding other industries, can be very complicated when trying to identify a cause.

A basic tenet of pharmacology and toxicology is that the dose makes the poison. Thus, in occupational hygiene (as in health physics, ergonomics and environmental engineering), limiting the dose of harmful chemicals, physiological stressors and the forces which act or impinge on the body, or allergenic, pathogenic or infectious agents, has become tantamount to making the workplace environment safe. Evaluating the level of risk involves determination of the dose and whether the dose is excessive (7). This hinges on the ability to measure the level of contamination, load, amount of body burden and to discriminate a 'safe' dose. Here, basic sciences provide experimental and epidemiological data on the dose-effect connection.

However, occupational hygienists speak of measuring exposures, not just dose. Dose is a term traditionally used in medicine that refers to the administration or intake of a specific amount of medicinal drugs. In radiation, the term 'dose' is also used in reference to measurements of the amount of energy absorbed per unit mass of tissue. In noise, dose refers to the cumulative amount of energy (sound pressure) impacting the eardrum per unit of time, namely the workday. Other than for radiation or noise, the term is used selectively by occupational hygienists. Hygienists conduct measurements of the work and environment to establish objective evidence about the severity of the risks, indicating where there is a need to protect individuals and/or control the threat by reducing the level of risk $(4,5)$.

Semantics aside, workplace dosimetry measurements are performed to quantify the level of exposure (ie, to estimate dose, whether toxin uptake, energy directed at tissues, biomechanical forces or cumulative load on the body due to heat stress, or other variables). Occupational hygienists determine the level of risk by analysis of the work, and by measuring conditions in the work environment to quantify these risks. The analysis involves judgements about the magnitude of the threat to health, safety and well-being, and knowledge of factors mitigating harm.

As the final objective, occupational hygienists use the information about exposures in the workplace to control the risks to individuals. In practice, this means controlling the risks to an 'acceptable level'. This is not the same as the 'no effect' level or the 'safe' level. 'No effect' can, of course, be achieved by ensuring 'no exposure', but total elimination of the causal agent is usually not achievable without serious practical implications for workers, their families, the work and the employers. The strategies used to control the exposures can seek to reduce emissions by modifying the work or equipment, to contain emissions or forces before they affect the worker, or 
if neither is feasible, to shield and protect the worker $(4,5)$. The so-called 'safe limit', as the best available guidelines acknowledge (8), will protect the majority of the individuals most of the time, not everyone all the time.

\section{TOPICAL ISSUES IN OCCUPATIONAL HYGIENE}

In the area of occupational hygiene there are several issues of topical interest. These are also of interest to other fields such as environmental health, toxicology, medicine and other hygiene sciences.

\section{Occupational carcinogens}

The International Agency for Research on Cancer has identified 55 agents, which at this time are known to cause cancer or are considered probable human carcinogens. The National Toxicology Program in the United States has a different system of classification. It categorizes 58 substances as known carcinogens and another 188 as reasonably likely cancer-causing agents.

With so many lives touched by cancer, the assurances of hygienists cannot seem to go far enough (9). Here is how the situation materializes at work - workers chat over lunch, at coffee and other occasions where they socialize with each other. They share experiences, personal knowledge and provide support to each other. As the information is pooled and shared, they soon perceive a 'cancer cluster' in the workplace or a connection to work, which simply does not exist, or at least question whether there is a connection to work. Professionals involved in community and public interest sessions on environmental subjects (location of a dump site, a nuclear power site or an abandoned smelter) also see and must deal with the dangers of these popular assumptions (10).

The National Cancer Institute's 'A to Z list of cancers' (11), identifies in excess of 200 different types of cancer, with 13 common cancer types. This melding of cancer into a single disorder 'an unbeatable disease' - helps to facilitate speculation in all settings. Occupational exposures account for only a minor proportion of the total cancers in the entire population (12). This is where hygiene communications need to start.

\section{Indoor air quality}

The observed effects of poor indoor air quality (IAQ) are lethargy, headaches, burning eyes, dry cough, itchy or irritated skin, inability to concentrate and other putative health problems. Occurrences may be transient, irregular or unpredictable, may be inconsistent between different individuals even in the same location, and may emerge as a ground swell among a percentage of the population. Identifying the common exposure, in an epidemiological sense, may be difficult $(13,14)$. 'Where?' is easier to define. The IAQ issue is always associated with a place (ie, the office, school or home). Problems are said to resolve after leaving, and then seem to reappear on return to the same place. Therefore, the affected individuals believe the environment to be the origin.

Uncertainty can fuel speculation when publicly broadcast news announcements, information on the Internet or from coworkers describe problems elsewhere (15). Initially, this phenomenon was called 'sick building syndrome', which may be closer to the truth (ie, it is often the building which is sick, not the occupants!).

These types of putative poor air quality (often environmental) situations, may have no obvious sources for contamination or exposure, no vulnerable points for discharges or emissions into the breathing air, and conditions are usually governed by reasonable standards of care. Compared with factories, construction sites, manufacturing operations, mines and processing plants, the indoor environments of these buildings are so much cleaner and the persons within them are at much lower risk. Slow release of gases and organic vapours from furnishings, finishes and building construction materials, typically result in exposures to contaminant concentrations, which are well below established dose-effect levels (14).

The majority of these health complaints are comfort issues, not symptoms of ill-health related to contamination of air supply. While they appear to be mysterious, quite often the explanation is mundane. Problems include poor fit of the mechanical air handling systems, the way they are operated and the current configuration, or modified use of the working and living space in the building or home (14). Air quality issues are a typical problem where there is not enough turnover of fresh air for the level of usage, causing conditions that are stuffy or stale, and where air is inadequately conditioned for temperature (too hot or too cold) and humidity (dry in winter and humid in summer). They also occur if there is discomfort where air movement produces excessive draft, where functionality of the building or interior space design suffers at the expense of form, and where aging building systems and construction materials begin to show the effects of wear and tear.

\section{Mold exposure}

Mold exposure is a specific example of an IAQ issue, which occupational hygienists, environmental public health officers, property managers and contractors frequently contend with. The public has become aware that molds have a potential to cause adverse health effects, but the fact that molds are part of our natural everyday environment has escaped recognition. Mold growth can trigger allergic or pseudoallergic reactions, including asthma, in susceptible individuals. For this reason, efforts should be made to control the growth and spread of molds inside of buildings by eliminating sites of excess moisture accumulation or condensation, repair of water leaks, and better maintenance and clean up of water-damaged building materials (16-18).

There has not been a balanced perspective on this topic. Mold concerns often seem to be out of proportion relative to the risks in the office, home or school environment. The world of molds is underexplored, but microbiologists have long known that molds can illicit allergic responses, and some emit toxins and irritants. However, in most everyday circumstances in which mold is present in the office, school or home, the potential severity is limited and insufficient to produce effects on a widespread scale. Mitigation measures can almost always be successfully instituted. The scientific community has not participated effectively in the dialogue, while the abatement industry has done particularly well.

\section{The next pandemic or bioterrorism}

There are professionals who say that all organizations should begin preparing for the next influenza pandemic (19). Certainly it is hard to argue against such a good cause, but the same rationale can be used with endless justifications, and not just in hygiene. If we do not act, what will happen? While acknowledgement of these types of possibilities is wise, if too much attention is diverted from the real problems of today, there will be no need to worry about tomorrow! A few years ago, parallels were seen with the dreaded ' $\mathrm{Y} 2 \mathrm{~K}$ bug' predicted to afflict computers, 
and enormous effort and attention were spent on preparations, which in the end fizzled.

There is no need to search for the next pandemic. They exist right now! At this time, Africa is undergoing a massive depopulation from HIV, with the selective loss of entire generations of young adults, leaving behind young children and the elderly to cope (20). Here in North America, we are told to prepare for West Nile Virus, yet malaria kills countless more everyday globally. The threat of HIV in our society has not disappeared, even though it may be better managed and understood, with programs to control bloodborne pathogens in the workplace, education on sexually transmitted diseases and screening of blood supply. Thinking only in the context of the developed world blinds us to the big picture - pandemics are here.

The root issues in some of these cases are far beyond hygiene alone, but they complicate the jobs of environmental hygienists. In this regard, there is a growing sense of insecurity among the public in our society. This produces a heightened sensitivity to risk, coupled with an insular view of our day-today world. These factors are beyond hygiene interventions alone, but suggest a need for understanding social psychology and effective risk communication.

\section{CONCLUDING REMARKS}

Hygiene requires the application of skill and motivation to hazard management, to control risks and minimize harmful exposures. Hygienists are disguised under various occupations as engineers, scientists, medical officers, environmental and public health professionals, and other occupations serving to protect the health and well-being of individuals and their communities in all settings. The breadth of hygiene science needs to be appreciated to understand hygienists' collective impact on society.

\section{REFERENCES}

1. Curtis VA. A natural history of hygiene. Can J Infect Dis Med Microbiol 2007;18:11-4

2. Goldner M. In: Rochon M, Goldner M, eds. The status of hygiene Stanier workshop roundtable at Vancouver, 2004. <www.stanier.ca> (Version current at February 6, 2008).

3. Sigerist HE. In: Cumberlege G, ed. Landmarks in the History of Hygiene. London: Oxford University Press, 1956.

4. Plog B. Overview of industrial hygiene. In: Plog B, Quinlan J, eds. Fundamentals of Industrial Hygiene, 5th edn. Illinois: National Safety Council, 2002:3-32.

5. Telisman S. Toxicology: effects of age, sex and other factors. In: Stellman J, McCann M, Warshaw L, et al, eds. Encyclopaedia of Occupational Health and Safety, 4th edn. Geneva: International Labour Office 1998;1:3.16-8.

6. Doull J. Factors influencing toxicology. In: Doull J, Klassen C, Amdur M, eds. Casarett and Doull's Toxicology: The Basic Science of Poisons, 2nd edn. New York: Macmillan Publishing Co, 1980:70-83.

7. Ottoboni MA. The Dose Makes the Poison: A Plain Language Guide to Toxicology. Berkeley: Vincente Books, 1986:32-8.

8. American Conference of Governmental Industrial Hygienists. Statement of position regarding TLVs and BEIs and introduction to the chemical substances. TLVs and BEIs Based on the Documentation of the Threshold Limit Values for Chemical Substances and Physical Agents \& Biological Exposure Indices. Cincinnati: Signature Publications, 2007:v-vii;3-9.

9. Morrison C. Carcinogens in the workplace: Preventing occupational cancer. In: Veazey G, ed. The Synergist. Fairfax: American Industrial Hygiene Association, 2007:18:32-5.

10. Sandman P. Responding to Community Outrage: Strategies for Effective Risk Communication. Fairfax: American Industrial Hygiene Association, 1993:109.
Hygiene is broader than risk management and control of diseases and ill-health; health and well-being are not just the absence of disease. Professionals and the lay public look to hygienists for answers to newly identified or perceived risks where regulators of occupational, community and environmental health are not able to keep up. The scope of hygiene science continues to enlarge. Hygienists are among those professionals who recognize and explain mitigating factors and determine 'true risks'.

In occupational hygiene, there is great concern about the rate of introduction of new chemicals, which vastly outpaces the development of test methods available to study or quantify them. This has created a worrisome void between the ability to identify and regulate chemical substances, as well as a need for new methods of air sampling, exposure evaluation and analytical methods. In environmental public health hygiene, the same type of concerns can be found about potential new infectious diseases, more virulent strains or transfer of pathogens.

Hygienists of all descriptions must work together to develop control strategies for eliminating or mitigating these exposures. This can be done most effectively when there is a true appreciation of the expanding role of hygiene, and appreciation of the contributions that each discipline can bring to their community, workplace and environment.

ACKNOWLEDGEMENTS: The author thanks Dr Morris Goldner of the Stanier Institute at Brock University (St Catherines, Ontario) for suggesting the present paper, for the opportunity of exchanging insights and for his dedication to this cause. The author also thanks Dr Harding le Riche and Ms Shawna Bourne for reading and commenting on the manuscript.
11. National Cancer Institute. A to $Z$ list of cancers. <www.cancer.gov> (Version current at February 6, 2008).

12. Gustavsson P. Cancer: Prevention. In: Stellman J, McCann M, Warshaw L, et al, eds. Encyclopaedia of Occupational Health and Safety, 4th edn. Geneva: International Labour Office, 1998:1:2.14-8.

13. Health Canada. Indoor air quality in office buildings: A technical guide. In: McDonnell J, Sheffer M, eds. Ottawa: Minister of Supply \& Services Canada, 1995:55.

14. Molhave L. The Sick building syndrome (SBS) caused by exposure to volatile organic compounds. In: Weekes D, Gammage R, eds. The Practitioner's Approach to Indoor Air Quality Investigations. Akron: The American Industrial Hygiene Association, 1989:1-18.

15. Bessa-Morey S, Weekes D. Indoor air quality practice: Art, science and chicken soup. In: Veazey G, ed. The Synergist. Fairfax: American Industrial Hygiene Association, 2007:18:40-2.

16. Office of Air and Radiation, Indoor Environments Division. Mold Remediation in Schools and Commercial Buildings. Pennsylvania: US Environmental Protection Agency, 2001.

17. World Health Organization. Indoor Air Quality: Biological Contaminants. Copenhagen: WHO Regional Publications, 1988:8-14;24-39.

18. Occupational Health and Safety Administration. Preventing Mold-Related Problems in the Indoor Workplace: A Guide for Building Owners, Managers and Occupants. Washington: US Department of Labor, 2006:32.

19. Ignacio J. Effectively assessing exposure to pandemic influenza: Working smarter to protect your personnel. In: Wassyng L, Brown S, eds. The Synergist. Fairfax: American Industrial Hygiene Association, 2006:17: 36-40.

20. Lewis S. Pandemic: My country is on its knees. Race Against Time: CBC Massey Lecture Series. Toronto: House of Anansi Press Inc, 2005:37-69. 


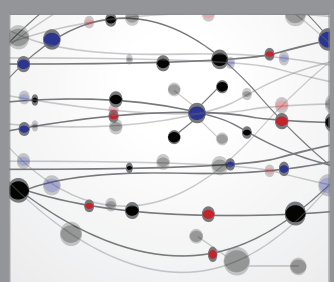

The Scientific World Journal
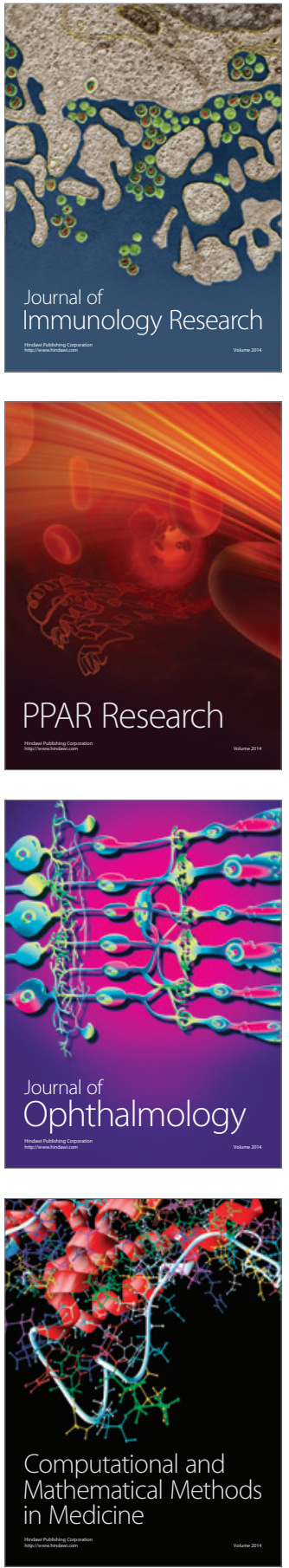

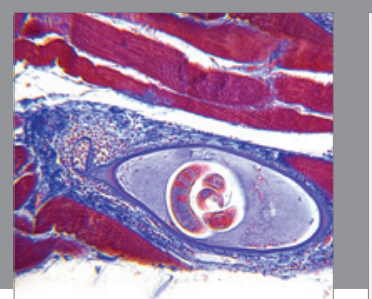

Gastroenterology Research and Practice

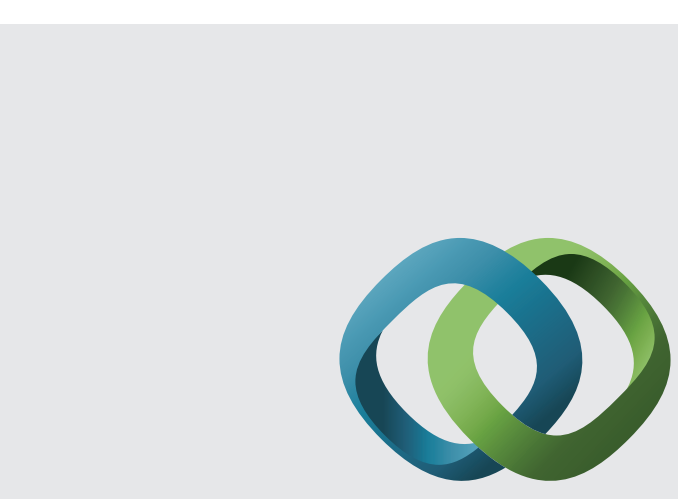

\section{Hindawi}

Submit your manuscripts at

http://www.hindawi.com
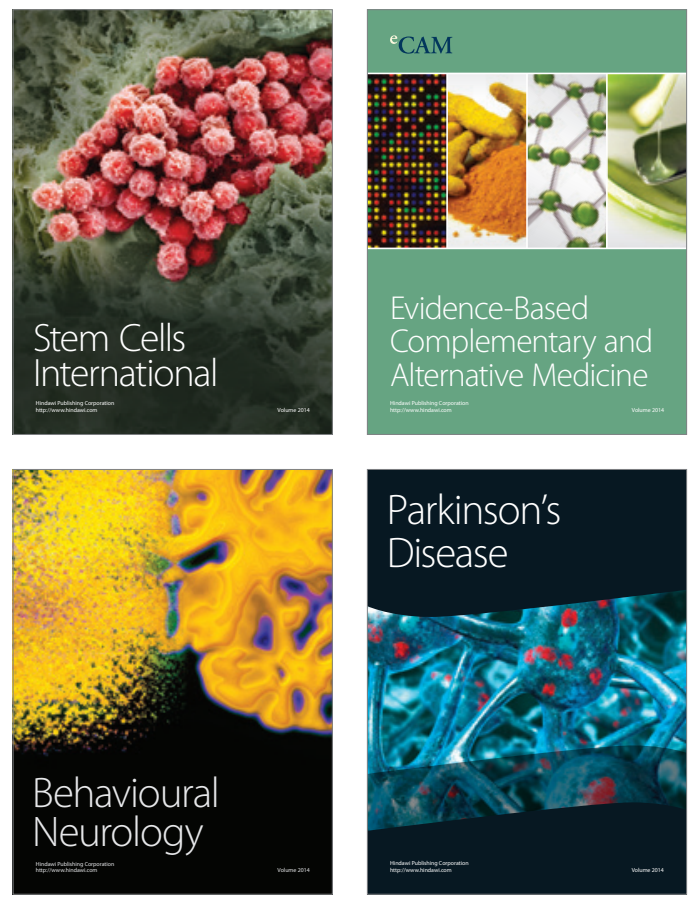
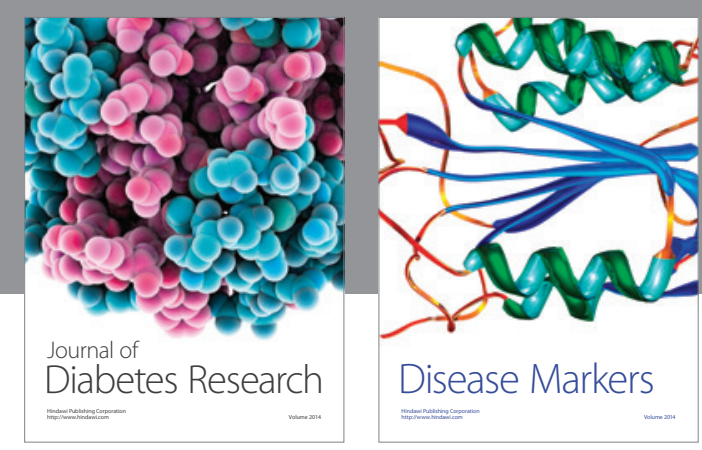

Disease Markers
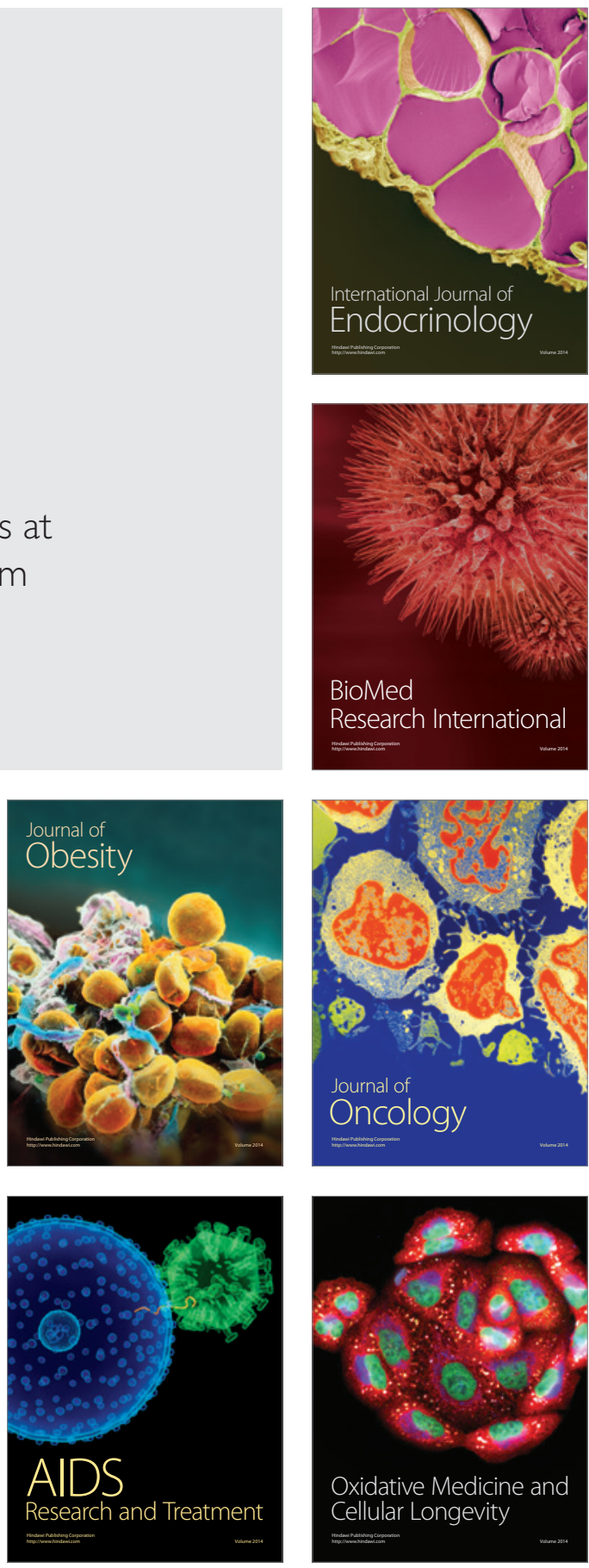